\title{
Chorioallantoic Membrane
}

National Cancer Institute

\section{Source}

National Cancer Institute. Chorioallantoic Membrane. NCI Thesaurus. Code C28216.

An extraembryonic, vascular structure that is found in the eggs of amniotes; in humans

the inner membrane forms the amniotic sac, and the outer membrane forms the chorion, which is part of the placenta. 